\title{
Modeling of Residual Stress Distribution for Components Manufactured by Selective Laser Melting
}

\author{
Tong $\mathrm{Ye}^{1}$, Xiaohui Jiang ${ }^{1, *}$, Miaoxian Guo ${ }^{1}$, Vladimir Kuptsov ${ }^{2}$ and Sergey Fedorov ${ }^{2}$ \\ ${ }^{1}$ University of Shanghai for science and technology, School of Mechanical Engineering, CN-200093, Shanghai, China \\ ${ }^{2}$ Moscow State Technological University "STANKIN", RU-127055, Moscow, Russia
}

\begin{abstract}
In this paper, the selective laser melting (SLM) simulation analysis of components is carried out. The residual stress distribution of the formed part was predicted, and the influence of process parameters such as exposure time, laser power and laser scanning speed on the residual stress of the SLM formed part was analyzed. It was found that the residual stress concentration of the formed part was in the middle of the upper surface or the bottom surface. In addition, the laser power and the laser scanning speed have a great influence on the residual stress of the formed part. The results of this study lay a theoretical and experimental basis for the optimization of residual stress and quality control of SLM components.
\end{abstract}

\section{Introduction}

Selective laser melting (SLM) is a typical additive manufacturing technology. This technology is used to produce a high-performance metal part with complex threedimensional structure by completely melting the metal powder in the laser selection zone, cooling and solidifying by heat dissipation, and layer-by-layer stacking ${ }^{[1]}$. The obtained metal parts have low porosity and favorable mechanical properties ${ }^{[2,3]}$. However, due to the concentrated energy and high power of the laser, the temperature distribution is not balanced, and , thus, there exist a high residual stress inside the part being formed $t^{[4,5]}$.

In the recent years, many studies on SLM have been performed. For example, Kimura et al. studied the microstructure and mechanical properties of SLM parts prepared under optimal laser irradiation conditions[6]. Parry et al. analyzed the effects of different scanning strategies on the residual stress distribution of parts being formed by developing a thermodynamic model[7]. Matsumoto et al. used the finite element method to study the elastic deformation and heat conduction of SLM parts, and concluded that the deformation degree of SLM formed parts is proportional to the length of laser scanning[8].

Jiang et al. studied the prediction and control of the residual stress of the parts, and proposed a residual stress volume model to evaluate the residual stress of the generated surface and subsurface[9]. Dai et al. compared the effects of different laser scanning methods on the stress distribution of formed parts[10].

Based on the aforementioned analysis and comparisons, we investigate the relationship between the re- sidual stress of the SLM part and the process parameters of the SLM process with accounting or the actual situation in the forming process, measurements of the residual stress of the SLM formed parts with different process parameters and comparison of measirements with simulations. The key parameters controlling impacts of the process parameters on the residual stress of the formed part and the residual stress in the SLM process have been derived and discussed.

\section{Experiments}

\subsection{Experimental procedure}

The process parameters that can be changed in the molding process of the SLM equipment used in this paper are laser scanning strategy, scanning speed, preheating temperature, exposure time, laser power and so on.

According to the different process parameters, the difference of residual stress of the SLM parts was compared, and the influence of different process parameters on the residual stress of the sample was studied.

The process parameters of this equipment are shown in Table 1. The sample used is AlSi10Mg powder with a particle size of $50 \mu \mathrm{m}$. The chemical composition of the powder is shown in Table 2.

In this experiment, the residual stress of the sample was tested using the Tec4000 X-ray diffraction system model (Figure. 1(a)). The distribution of sample residual stress test points is shown in Figure. 1(b).

e-mail: jiangxh@usst.edu.cn 
Table 1. Parameters of selective laser melting

\begin{tabular}{|c|c|}
\hline Parameters & Value \\
\hline Laser power & $200 \mathrm{~W}, 300 \mathrm{~W}, 400 \mathrm{~W}$ \\
\hline Scanning speed & $\begin{array}{c}100 \mathrm{~mm} / \mathrm{s}, 200 \mathrm{~mm} / \mathrm{s}, 300 \\
\mathrm{~mm} / \mathrm{s}\end{array}$ \\
\hline Exposure time & $112 \mu \mathrm{s}, 140 \mu \mathrm{s}, 168 \mu \mathrm{s}$ \\
\hline
\end{tabular}

Table 2. Chemical composition of AlSi10Mg

\begin{tabular}{|c|c|c|c|c|c|c|}
\hline Elements & $\mathrm{Si}$ & $\mathrm{Mg}$ & $\mathrm{Fe}$ & $\mathrm{Cu}$ & $\mathrm{Mn}$ & $\mathrm{Al}$ \\
\hline $\begin{array}{c}\text { Composition } \\
\text { (wt\%) }\end{array}$ & 11 & 0.6 & 2 & 0.6 & 0.35 & $\mathrm{Bal}$ \\
\hline
\end{tabular}

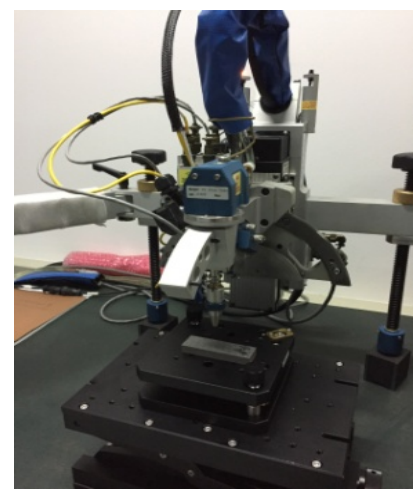

(a) Residual stress test

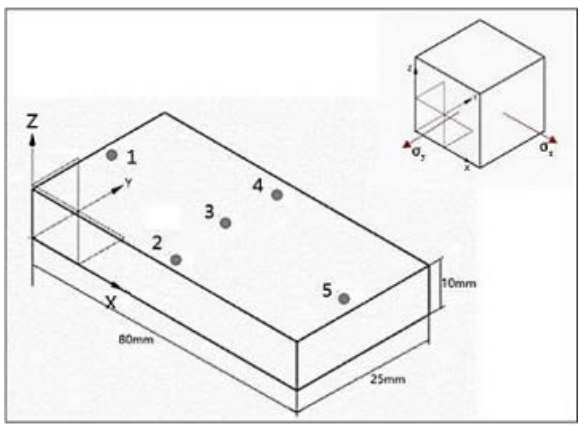

(b) Test point distribution

Fig. 1. Test scheme for sample residual stress

\subsection{Model}

The selection of heat source model in the simulation of SLM process has great influence on the calculation precision of stress field. The heat source model with uniform distribution is mostly used in the early research, and the Gaussian distribution heat source model, double elliptical heat source model and combined heat source model are widely used at present. In this paper, considering the size of the powder and the gap between the powder, the laser can radiate directly to the formed surface, so that the powder is melted in an instant. Therefore, the Gaussian cylinder heat source model with uniform dis- tribution in the height direction is used in this paper. The heat source equation was written as follows:

$$
q(x, y)=\frac{2 A P}{\pi \omega^{2}} \exp \left(-2 \frac{x^{2}+y^{2}}{\omega^{2}}\right)
$$

Where $\mathrm{q}(\mathrm{x}, \mathrm{y})$ is the laser power density; $\mathrm{P}$ is the laser power; $\omega$ is the laser spot diameter; $\mathrm{A}$ is the absorption rate of the powder bed to the laser; $x^{2}+y^{2}$ is the distance from any point of the powder bed to the center of the spot.

The generalized three-dimensional heat conduction equation in the rectangular coordinate system is as follows:

$$
\operatorname{c\rho } \frac{\partial T}{\partial t}=k\left(\frac{\partial^{2} T}{\partial x^{2}}+\frac{\partial^{2} T}{\partial y^{2}}+\frac{\partial^{2} T}{\partial z^{2}}\right)
$$

Where $\mathrm{c}$ is the heat capacity of the material; $\rho$ is the density of the material; $\mathrm{k}$ is the thermal conductivity of the powder bed.

In order to avoid a large temperature gradient in the process of powder melting, the whole powder bed should be preheated before melting, so that the uniform preheating temperature is $T_{0}$.

$$
\left.T(x, y, z, t)\right|_{t=0}=T_{0}
$$

There is heat convection and thermal radiation on the surface of the powder bed and the surrounding environment, so the temperature field model are as follows:

$$
-\left.\mathrm{k} \frac{\partial T}{\partial z}\right|_{z=0}+h\left(T_{S}-T_{E}\right)+\sigma \epsilon\left(T^{4}-T_{E}^{4}\right)=q
$$

Where $T_{S}$ is the surface temperature of the powder bed, $T_{E}$ is the ambient temperature, $h$ is the convective heat transfer coefficient, and $\varepsilon$ is the thermal radiation coefficient, $\sigma$ is the Stefan-Boltzmann constant about $5.67 \times 10^{8} \mathrm{~W} /\left(\mathrm{m}^{2} \mathrm{~K}^{4}\right)$.

After the parameters of the model are determined, the three-dimensional finite element model is established as shown in Figure 2.

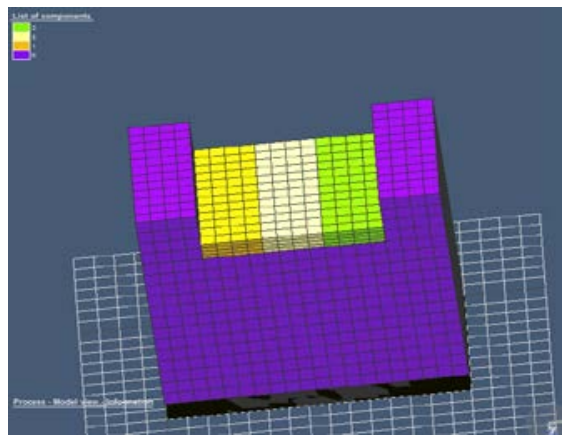

Fig. 2. Three-dimensional finite element model 


\section{Result and discussion}

\subsection{Residual stress result of simulation and ex- periment}

According to the process parameter setting of the SLM process in Table 1, the residual stress of the test points obtained by the simulation is compared with the data measured by the experiment. As shown in Figure 3, it can be seen that the error between the experimental results and the simulation results is small. It indicates that the parameters of the heat source model and process parameters in the simulation are consistent with the actual SLM forming process, which proves that the method can be used to predict and calculate the residual stress of SLM formed parts.

Table 3 shows the residual stress values at each point of the sample with different exposure time. Under different exposure time, the maximum residual stress of sample 2, sample 3 and sample 4 is $81.3 \mathrm{MPa}, 73.9 \mathrm{MPa}$, 65.8MPa, the residual stress of point 1 has a slight decrease. However, with the decrease of exposure time, the increase of residual stress is not particularly obvious.

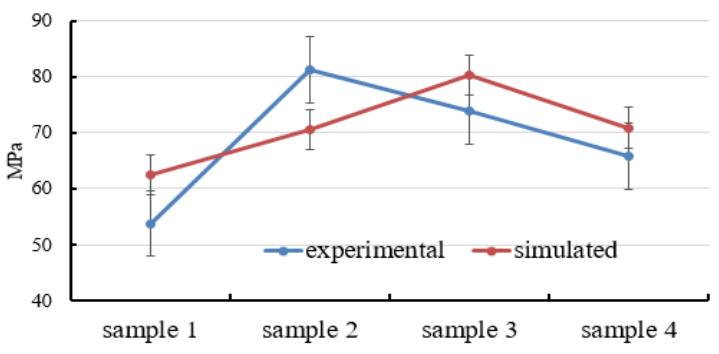

Fig. 3. Experimental results and simulated results of sample residual stress

\subsection{Effect of laser power on residual stress}

Figure 4 shows the residual stress distribution of the sample during SLM simulation with different laser power. When the laser power is $200 \mathrm{~W}$, the residual stress of the sample is $45 \mathrm{MPa}$ to $90 \mathrm{MPa}$, and the residual stress at the midpoint is $97 \mathrm{MPa}$. When the laser power is $300 \mathrm{~W}$ and $400 \mathrm{~W}$, the residual stress of the sample varies from $50 \mathrm{MPa}$ to $115 \mathrm{MPa}$ and $53 \mathrm{MPa}$ to $135 \mathrm{MPa}$, respectively. The residual stress nephogram of the sample is shown in Figure 6. It can be seen that as the laser power increases, the residual stress gradually increases, and the residual stress in the bottom region of the sample is larger.

It found that in the SLM process, powder will absorb large energy and produce molten pool because of the laser beam, which can promote the heat transfer of interlaminar structure, reduce the thermal cycle inhomogeneity in the process of laser scanning, and improve the quality of the specimen. But when the laser power is too high, the laser energy absorbed by the powder increases to form a large molten pool, which leads to a significant decrease in viscosity and a decrease in the solidification rate of the molten pool, resulting in reduced quality of SLM formed parts.

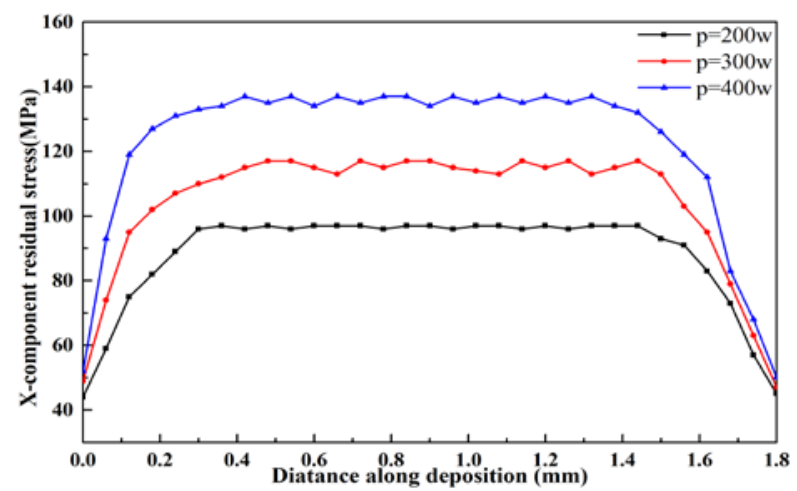

Fig. 4. Residual stress of sample with different laser power

\subsection{Effect of laser scanning speed on residual} stress

The residual stress of the sample with different laser scanning speed is shown in Figure 5. When the laser scanning speed is $100 \mathrm{~mm} / \mathrm{s}$, the residual stress at the midpoint is 95MPa, the scanning speed increases from $200 \mathrm{~mm} / \mathrm{s}$ to $300 \mathrm{~mm} / \mathrm{s}$, and the residual stress at the midpoint of the sample increases from 123MPa to 130MPa. The residual stress nephogram of different laser scanning speed samples is shown in Figure 7. As the laser scanning speed increases, the residual stress changes very obviously. And both Figure 6 and Figure 7 show that the stress concentration position is at the bottom of the sample and in the middle of the surface.

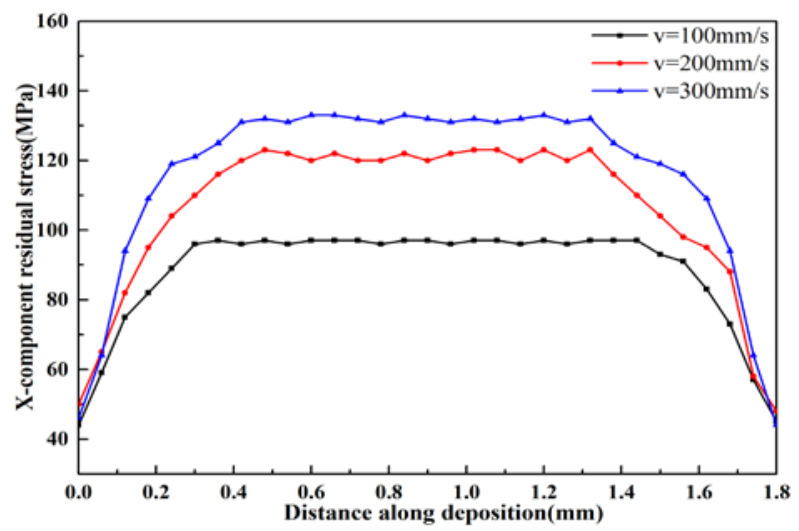

Fig. 5. Residual stress of sample with different scanning speed

As the laser scanning speed is increased, the input energy of the laser is reduced, the shorter the residence time of the laser beam, the higher the cooling speed of the forming area, the temperature gradient is increased, the non-uniform thermal deformation behavior of the formed part is more obvious, and the residual stress of the SLM formed part is increased. 
Table 3. Test of residual stress of sample

\begin{tabular}{|c|c|c|c|c|c|c|}
\hline & $\begin{array}{c}\text { Exposure } \\
\text { time } \\
(\mu \mathrm{s})\end{array}$ & $\begin{array}{c}\text { Point 1 } \\
\text { residual stress } \\
(\mathrm{MPa})\end{array}$ & $\begin{array}{c}\text { Point 2 } \\
\text { residual stress } \\
(\mathrm{MPa})\end{array}$ & $\begin{array}{c}\text { Point 3 } \\
\text { residual stress } \\
(\mathrm{MPa})\end{array}$ & $\begin{array}{c}\text { Point 4 } \\
\text { residual stress } \\
(\mathrm{MPa})\end{array}$ & $\begin{array}{c}\text { Point 5 } \\
\text { residual stress } \\
(\mathrm{MPa})\end{array}$ \\
\hline Sample 1 & 100 & 19.6 & 49 & 53.8 & 78.6 & 56.1 \\
\hline Sample 2 & 112 & 14.1 & 42.1 & 81.3 & 49.9 & 37.6 \\
\hline Sample 3 & 140 & 13.3 & 23.4 & 73.9 & 42.6 & 34.7 \\
\hline Sample 4 & 168 & 15 & 38.3 & 65.8 & 49.9 & 27.9 \\
\hline
\end{tabular}

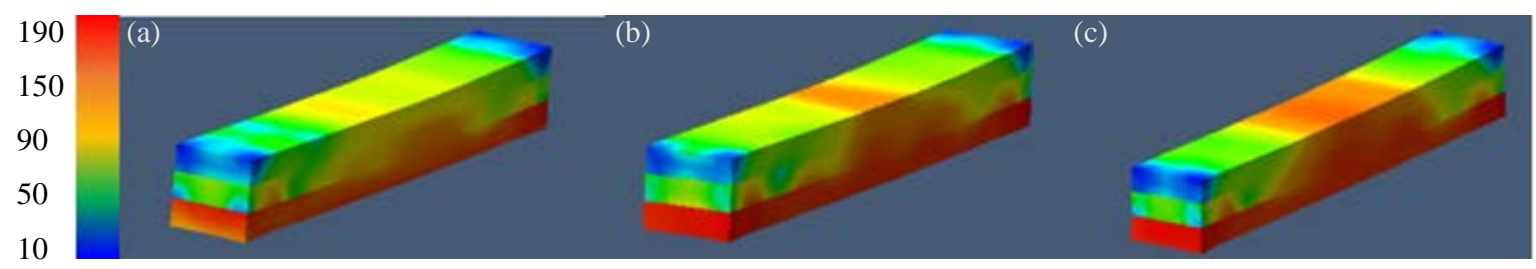

Fig. 6. The residual stress nephogram of the sample (MPa): (a) 200W; (b)300W; (c)400W

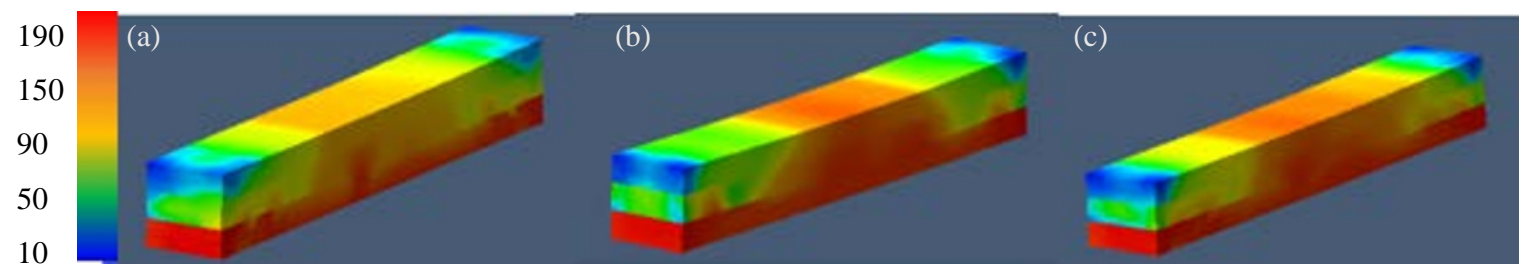

Fig. 7. The residual stress nephogram of the sample (MPa): (a) $100 \mathrm{~mm} / \mathrm{s}$; (b)200mm/s; (c) $300 \mathrm{~mm} / \mathrm{s}$

\section{Conclusion}

The simulation results show that the influence of different process parameters on the residual stress of the SLM parts is different. The influence of exposure time on the final residual stress of the formed part is very limited, while the scanning speed can considerably affect the temperature field of the formed part, and cause changes in the final residual stress. The laser power has a significant effect on the residual stress of the part being formed. In addition, the central part of the surface of the sample of the SLM and the stress concentration in the bottom of the sample were found.

Therefore, a careful setting of each process parameter is needed to control the residual stress of the SLM formed part and to improve the quality of the formed part.

Acknowledgement. The authors would like to acknowledge the support of Innovation Funding of Shanghai Aerospace Science and Technology. (No. SAST2016054). We also thank the Center of Collective Use of MSUT "STANKIN" for providing resources.

\section{References}

1. H. Ali, H. Ghadbeigi, K. Mumtaz., Materials Science \& Engineering A, 712, 175-187 (2017)

2. Y. Li, K. Zhou, P. Tan, et al., International Journal of Mechanical Sciences, 136, 24-35 (2018)

3. T. Debroy, H.L. Wei, J.S. Zuback, et al., Progress in Materials Science, 92, 112-224 (2017)

4. S. Leuders, M. Thöne, A. Riemer, et al. International Journal of Fatigue, 48, 300-307 (2013)

5. A. Salmi, E. Atzeni, Virtual \& Physical Prototyping, 12(2), 153-160 (2017)

6. T. Kimura, T. Nakamoto, Materials \& Design, 89, 1294-1301 (2015)

7. L. Parry, I. Ashcroft, D. Bracket, et al., Key Engineering Materials, 627, 129-134 (2015)

8. M. Matsumoto, M. Shiomi, K. Osakada, et al., International Journal of Machine Tools \& Manufacture, 42(1), 61-67 (2002) 
9. X. Jiang, X. Kong, Z. Zhang, et al., International Journal of Mechanical Sciences, 167, 105162 (2019)

10. K. Dai, L. Shaw, Rapid Prototyping Journal, 8(5), 270-276 (2002).
11. S.N. Grigoriev, V.A. Sinopalnikov, M.V. Tereshin, and V.D. Gurin, Measur. Techn., 55(5), 555-558 (2012)

12. S.N. Grigoriev, M.P. Kozochkin, F.S. Sabirov, and A.A. Kutin, Proc. CIRP, 1, 599-604 (2012) 